\title{
Effects of Continuous Cropping of Dictyophora on Soil Physical and Chemical Properties, Microbial Biomass and Enzyme Activity
}

\author{
Long Tong, Hongyan Li, Xiaoming Liu, Bin Li*, Lijie Chen, Guilan Chen, Xiaoying Zeng, Yanghui Geng \\ Chongqing Forestry Science Research Institute, Chongqing 400036 \\ *Correspondence Author
}

\begin{abstract}
The continuous obstacle of Dictyophora indusiata has become the one of the main factors affecting the healthy development of $D$. indusiata industry. In order to study the effects of continuous cropping of $D$. indusiata on the soil environment, four treatments were used in this study: no planted (CK), planted for 1 years (1Y), continuous cropping for 2 years $(2 Y)$ and continuous cropping for 3 years (3Y), to determined of the yield of D. indusiata, soil physical and chemical properties, microbial content and enzyme activity. The results showed that the yield and soil $\mathrm{pH}$ value decreased with the increase of continuous cropping years, and the contents of organic matter, total nitrogen, total phosphorus and total potassium, C/N and C/P also increased with the increase of continuous cropping years. Soil availability decreased with the increase of continuous cropping years, the content of alkaline nitrogen, available phosphorus and available potassium decreased by $12.25 \%$, $28.91 \%$ and $24.86 \%$ at $3 Y$ compared with $1 Y$, respectively. The biomass of bacteria, actinomycetes and fungi and the total amount of microorganism in soil increased at $1 Y$ compared with $C K$, but with the increase of continuous cropping years, the biomass of bacteria and actinomycetes and the total amount of microorganism decreased significantly, while the biomass of fungi increased significantly; the continuous cropping of $D$. indusiata also decreased the value of bacteria/fungi in soil. The enzyme activities of the soil were higher than those of the unplanted plots, however, the activities of urease, catalase, peroxidase, sucrase, phosphatase and protease decreased with the increase of continuous cropping years. In a word, with the increase of continuous cropping, the acidity of rhizosphere soil increased, the availability of soil nutrients and the activity of soil enzymes decreased, the biomass of soil microorganisms, bacteria and actinomycetes decreased. However, the increase of fungal biomass led to the decline of soil texture.
\end{abstract}

Keywords: Dictyophora indusiata, Continuous cropping, Soil physicochemical properties, Soil microbial biomass, Soil enzyme activity.

\section{Introduction}

Dictyophora indusiata is a kind of edible and medicinal fungus (Cai et al. 2015), It has high nutritional value, including a large number of proteins, fats, total sugars, cellulose and polysaccharides, and also contains 8 kinds of amino acids necessary for human body (Ker et al. 2011). In recent years, the cultivation of $D$. indusiata has developed rapidly, the scale of cultivation expanded and yield increased continuously, the cultivation of $D$. indusiata has become an important economic source and regional characteristic industry for farmers (Lin et al. 2011). The cultivated land resources in China are relatively scarce, so making full use of the space under all kinds of bamboo forest and developing the edible fungus under the bamboo forest can alleviate the difficulty of the cultivated land shortage, which is also an important and potential development direction of the edible fungus industry at present (Lv et al. 2012). At present, the development of $D$. indusiata under the bamboo forest has encountered continuous cropping obstacles, after planting $D$. indusiata under the same bamboo forest for many years, even under the conventional management conditions, the production, quality and growth condition of $D$. indusiata planted in the second year of the same plot will decrease (Lv et al. 2012; Chang et al. 2013).

The reason of crop continuous cropping obstacle is mainly from soil, and it is the result of many comprehensive effects (Hou et al. 2016). After continuous cropping, the soil nutrients will change unevenly, which will cause the crop growth obstacles (Zhang et al. 2016; Chen et al. 2018). Continuous cropping of Panax notoginseng will enrich inorganic elements in soil and aggravate soil diseases (Liu et al. 2014). Studies on crops such as flue-cured tobacco (Ye et al. 2011; Gu et al. 2013), soybean (Wang et al. 1997; Xu et al. 1999) and peanut (Wu et al. 2006; Wang et al. 2011) have confirmed that continuous cropping can significantly affect the dry matter production and accumulation process of plants, and also significantly affect the distribution and distribution rate of assimilated products to economic organs after flowering, which may be an important cause of serious decline in crop economic yield under continuous cropping system. In continuous cropping, the structure of soil aggregate is destroyed, resulting in soil hardening and poor buffering (Wan 2011). For example, the continuous cropping of Gossypium spp will increase the soil specific gravity and bulk density, decrease the porosity (Chai et al. 2008). The soil enzyme activity can also reflect the transformation ability of nutrient elements and the change of soil biological activity in the soil ecosystem, which can be used to measure the health status of the soil. The activities of sucrase, urease and phosphatase were decreased with the extension of continuous cropping time (Sun et al. 2010; Dou et al. 2016). This is also found in the study of Poria cocos (Yu et al. 2009). Continuous cropping can disturb the ecological balance of soil microbes and change the population and function of soil microbes, which can directly affect the growth of crops (Yu et al. 2009; Chen et al. 2012). After 4 years of continuous cropping (Burley tobacco), the diversity of soil bacterial community decreased significantly, and the bacterial community structure became single (Chen et al. 2010). The cultivation of $D$. indusiata needs fertile and loose soil, high humus content, good permeability and hard to harden, the soil under the bamboo forest is very suitable (Zhen et al. 2001). All the raw 
materials left after the production of $D$. indusiata return to the soil, the main components of these raw materials are difficult to decompose lignin, etc., which can be used as raw materials for soil improvement and effectively improve the soil texture. However, under continuous cropping conditions, the accumulation of these lignin will be difficult to decompose by soil microorganisms in time, resulting in the decline of soil texture, which will affect the production of $D$. indusiata, and will change the growth conditions of trees and affect the growth of bamboo.

In some areas, the problem of continuous cropping obstacles has seriously affected the healthy development of $D$. indusiata industry (Shi 2018; Chen et al. 2017; Jiang 2011). In view of this, the yield and soil physicochemical properties and microbial diversity of $D$. indusiata after continuous $D$. indusiata under bamboo forest were studied. The purpose is to reveal the influence of continuous cropping of $D$. indusiata on soil structure, and to reveal the reasons for the change of soil structure in the process of continuous cropping of $D$. indusiata in combination with the analysis of soil physical and chemical properties, to provide a theoretical basis for the comprehensive analysis of the obstacles of continuous cropping of $D$. indusiata.

\section{Materials and Methods}

\subsection{Experimental Materials}

The experimental site is located at Lanfeng forest farm $\left(105^{\circ} 33.312^{\prime} \mathrm{E}, 29^{\circ} 17.031^{\prime} \mathrm{N}\right)$, Rongchang city, Chongqing province, China. The altitude is $480 \mathrm{~m}$, and the soil is mountain yellow soil with mean precipitation of $1099 \mathrm{~mm}$, annual average temperature is $17.8^{\circ} \mathrm{C}$, annual total accumulated temperature is $6482^{\circ} \mathrm{C}$. The frostless season more than 327 days, monthly extreme maximum temperature is $39.9^{\circ} \mathrm{C}(1972)$, and monthly extreme minimum temperature is $-3.4^{\circ} \mathrm{C}(1975)$, the daily mean temperature is stable through $12^{\circ} \mathrm{C}$, which is 265 days. The annual average sunshine time is 1282 hours, and the annual rainfall is $1111.8 \mathrm{~mm}$. The average DBH of bamboo forest was $7.9 \mathrm{~cm}$, and the average density of standing bamboo was 3780 plants $/ \mathrm{hm}^{2}$.

\subsection{Experimental Design}

This experiment period was continued 3 years, and the plot was designed in 2017, set up a sample land with $30 \mathrm{~m} \times 30 \mathrm{~m}$, continuous planting $D$. indusiata for 3 years treatment. Set up another sample land with $30 \mathrm{~m} \times 30 \mathrm{~m}$ in 2018 , continuous planting $D$. indusiata for 2 years. Set up the same size sample land in 2019, planting D. indusiata for 1 years. Set up a 30 $\mathrm{m} \times 30 \mathrm{~m}$ blank plot as control, the spacing of each plot was more than $10 \mathrm{~m}$, and set a buffer zone with a width of $5 \mathrm{~m}$ was set at the edge of each plot. There were four treatments in the experiment: the unplanting plot $(\mathrm{CK})$, planting one year in 2019 (1Y), continuous cropping two years from 2018 to 2019 (2Y), and continuous cropping three years from 2017 to 2019 (3Y). The quality and yield of $D$. indusiata was recorded for 3 consecutive years, and soil samples were collected in the second wave period of $D$. indusiata in 2019. Five sampling points were randomly set with the shape of "S", and using a sterilized shovel to obtain the surface soil samples in the range of $0 \mathrm{~cm}$ to $15 \mathrm{~cm}$ in the rhizosphere of $D$. indusiata, the rhizosphere soil adhered to the root surface was obtained by buffeting method and mixed. Finally, 5 randomly sampled points were mixed as a soil sample, and CK was collected in 2017. The soil samples were divided into two parts: one of them was screened by $2 \mathrm{~mm}$ sieve, to determine the physical and chemical properties of the soil after air drying; the other was used to pick up the stones and sundries and take them back to the laboratory for preservation at $-20^{\circ} \mathrm{C}$, to analyze the enzyme activity and microorganism.

\subsection{Experimental Methods}

Soil samples were air-dried and all soil physicochemical properties were determined by dry weight (Bao 2000). Soil $\mathrm{pH}$ shall be determined with acidimeter according to the water soil ratio of 2.5:1. Determination of soil organic carbon (SOC) and organic matter (SOM) by $\mathrm{H}_{2} \mathrm{SO}_{4}-\mathrm{K}_{2} \mathrm{Cr}_{2} \mathrm{O}_{7}$ wet oxidation method. Soil total nitrogen (TN) was determined using Kjeldahl's method, available nitrogen (AN) was determined using the alkali-hydrolytic diffusion method. Soil total phosphorus (TP) and available phosphorus (AP) were determined using molybdenum antimony contrast method. Soil total potassium (TK) and available potassium (AK) were determined by flame spectrophotometer method. Soil urease activity was measured using sodium phenol-sodium hypochlorite colorimetric method, phosphatase activity was measured using disodium phosphate colorimetric method, invertase activity was measured using 3,5-Dinitrosalicylic acid colorimetry method, protease activity was measured using chironolactone colorimetric method, catalase activity was measured using permanganate titration method, peroxidase and polyphenol oxidase activity were measured using pyrogallol colorimetry method. Soil microbial biomass was determined using phospholipid fatty acid (PLFA) analysis by gas chromatography mass spectrometrys. The determination of soil physical and chemical properties and microbial diversity was completed in the South economic forest product quality inspection center of Subtropical Forestry Research Institute, China Academy of Forestry Sciences.

\subsection{Statistical Analysis.}

Soil physical and chemical properties and bacterial diversity index were analyzed by Duncan's new method $(P<0.05)$ based on SPSS 22.0 software. Adopt the form of average value \pm standard error, and different letters in the same column showed significant differences.

\section{Results and Analysis}

\subsection{Quality and Yield of D. indusiata.}

The data show that continuous cropping of $D$. indusiata has a certain influence on quality and yield of $D$. indusiata. There was no significant difference in the length of $D$. indusiata treated with the increase of continuous cropping years. The 
fresh weight of the $3 \mathrm{Y}$ decreased significantly compared with $1 \mathrm{Y}$ and $2 \mathrm{Y}$, and decreased by $7.77 \%$ compared with $1 \mathrm{Y}$, decreased by $7.40 \%$ compared with $2 \mathrm{Y}$, but there was no significant difference between $1 \mathrm{Y}$ and $2 \mathrm{Y}$. The dry weight of $D$. indusiata decreased with the increase of continuous cropping years. There was no significant difference in water rate between different treatments. The yield of $D$. indusiata showed the minimum value at $3 \mathrm{Y}$, which was $40.15 \mathrm{~kg} / \mathrm{hm}^{2}$, significantly lower than $1 \mathrm{Y}$ and $2 \mathrm{Y}$.

Table 1: Effects of continuous cropping of $D$. indusiata on quality and yeild of $D$. indusiata

\begin{tabular}{cccccc}
\hline Treatment & $\begin{array}{c}\text { Length } \\
(\mathrm{cm})\end{array}$ & $\begin{array}{c}\text { Fresh } \\
\text { weight } \\
(\mathrm{g})\end{array}$ & $\begin{array}{c}\text { Dry weight } \\
(\mathrm{g})\end{array}$ & $\begin{array}{c}\text { Water rate } \\
(\%)\end{array}$ & $\begin{array}{c}\text { Yield } \\
\left(\mathrm{kg} / \mathrm{hm}^{2}\right)\end{array}$ \\
\hline $1 \mathrm{Y}$ & $20.36 \mathrm{a}$ & $19.82 \mathrm{a}$ & $1.96 \mathrm{a}$ & $90.11 \mathrm{a}$ & $53.81 \mathrm{a}$ \\
$2 \mathrm{Y}$ & $20.20 \mathrm{a}$ & $19.74 \mathrm{a}$ & $1.86 \mathrm{ab}$ & $90.58 \mathrm{a}$ & $50.49 \mathrm{a}$ \\
$3 \mathrm{Y}$ & $19.28 \mathrm{a}$ & $18.28 \mathrm{~b}$ & $1.71 \mathrm{~b}$ & $90.65 \mathrm{a}$ & $40.15 \mathrm{~b}$ \\
\hline
\end{tabular}

\subsection{Physicochemical Properties of Soil}

As shown in table 2, compared with $\mathrm{CK}$, the soil $\mathrm{pH}$ decreased significantly after continuous cropping of D. indusiata, the $\mathrm{pH}$ value of $1 \mathrm{Y}, 2 \mathrm{Y}$ and $3 \mathrm{Y}$ decreased by $8.74 \%, 11.66 \%$ and $13.72 \%$, respectively. The SOM content of $1 \mathrm{Y}, 2 \mathrm{Y}$ and $3 \mathrm{Y}$ increased significantly compared with $\mathrm{CK}$, but there was no significant difference between different years. The content of SOC increased gradually with the increase of continuous cropping years, and the SOC reached the highest level in $3 \mathrm{Y}$, which was $46.63 \mathrm{~g} / \mathrm{kg}$, and significantly increased by $100.7 \%$ compared with CK. The contents of TN, TP and TK in soil increased with the increase of continuous cropping years, and ranked as: $3 \mathrm{Y}>2 \mathrm{Y}>1 \mathrm{Y}>\mathrm{CK}$. The $\mathrm{AN}$ content of $1 \mathrm{Y}$ was increased by $35.55 \%$ compared with $\mathrm{CK}$, and that of $2 \mathrm{Y}$ was no significant difference compared with $\mathrm{CK}$, but it was decreased by $26.75 \%$ compared with $1 \mathrm{Y}$, and that of $3 \mathrm{Y}$ was the lowest, which was decreased by $12.25 \%, 35.27 \%$ and $11.62 \%$ compared with $\mathrm{CK}, 1 \mathrm{Y}$ and $2 \mathrm{Y}$, respectively. The AP content of $1 \mathrm{Y}$ was significantly higher than $\mathrm{CK}$, increased by $73.35 \%$, and that of $2 \mathrm{Y}$ and $3 \mathrm{Y}$ was significantly lower than $1 \mathrm{Y}$, but increased compared with $\mathrm{CK}$. The AK content increased first and then decreased with the increase of continuous cropping years, but it was higher than CK, which ranked as: $1 \mathrm{Y}>2 \mathrm{Y}>3 \mathrm{Y}>\mathrm{CK}$, the maximum value was $163.7 \mathrm{mg} / \mathrm{kg}$ at $1 \mathrm{Y}$.

\subsection{N/P, C/N and N/P Ratio in Soil}

The $\mathrm{C} / \mathrm{N}, \mathrm{C} / \mathrm{P}$ and N/P ratio in soil increased after continuous cropping of $D$. indusiata, and increased with the increase of continuous cropping years (Figure 1).

Table 2: Effects of continuous cropping of D. indusiata on soil physicochemical properties

\begin{tabular}{|c|c|c|c|c|c|c|c|c|c|}
\hline Treatment & $\mathrm{pH}$ & $\begin{array}{c}\text { SOM } \\
(\mathrm{g} / \mathrm{kg})\end{array}$ & $\begin{array}{c}\text { SOC } \\
(\mathrm{g} / \mathrm{kg})\end{array}$ & $\begin{array}{c}\mathrm{TN} \\
(\mathrm{g} / \mathrm{kg})\end{array}$ & $\begin{array}{c}\mathrm{TP} \\
(\mathrm{g} / \mathrm{kg})\end{array}$ & $\begin{array}{c}\text { TK } \\
(\mathrm{g} / \mathrm{kg})\end{array}$ & $\begin{array}{c}\mathrm{AN} \\
(\mathrm{mg} / \mathrm{kg})\end{array}$ & $\begin{array}{c}\text { AP } \\
(\mathrm{mg} / \mathrm{kg})\end{array}$ & $\begin{array}{c}\mathrm{AK} \\
(\mathrm{mg} / \mathrm{kg})\end{array}$ \\
\hline CK & $5.833 \mathrm{a}$ & $38.63 \mathrm{~b}$ & $23.23 \mathrm{~d}$ & $1.897 \mathrm{~d}$ & $0.378 \mathrm{c}$ & $13.73 \mathrm{c}$ & $182.0 \mathrm{~b}$ & $3.917 \mathrm{bc}$ & $106.5 \mathrm{c}$ \\
\hline $1 \mathrm{Y}$ & $5.323 \mathrm{~b}$ & $54.00 \mathrm{a}$ & $34.70 \mathrm{c}$ & $2.520 \mathrm{c}$ & $0.443 \mathrm{~b}$ & $14.28 \mathrm{bc}$ & 246.7 a & $6.790 \mathrm{a}$ & $163.7 \mathrm{a}$ \\
\hline $2 \mathrm{Y}$ & $5.153 \mathrm{c}$ & $51.60 \mathrm{a}$ & $39.53 \mathrm{~b}$ & $2.703 \mathrm{~b}$ & $0.491 \mathrm{a}$ & $16.11 \mathrm{ab}$ & $180.7 \mathrm{~b}$ & $4.697 \mathrm{~b}$ & $128.3 \mathrm{~b}$ \\
\hline $3 \mathrm{Y}$ & $5.033 \mathrm{c}$ & $55.60 \mathrm{a}$ & $46.63 \mathrm{a}$ & $3.097 \mathrm{a}$ & $0.511 \mathrm{a}$ & $16.70 \mathrm{a}$ & $159.7 \mathrm{c}$ & $4.827 \mathrm{~b}$ & $123.0 \mathrm{bc}$ \\
\hline
\end{tabular}

Note: Data shows average value \pm standard errors, and different letters indicate significant differences between treatments $(P<0.05)$, similarly hereinafter.
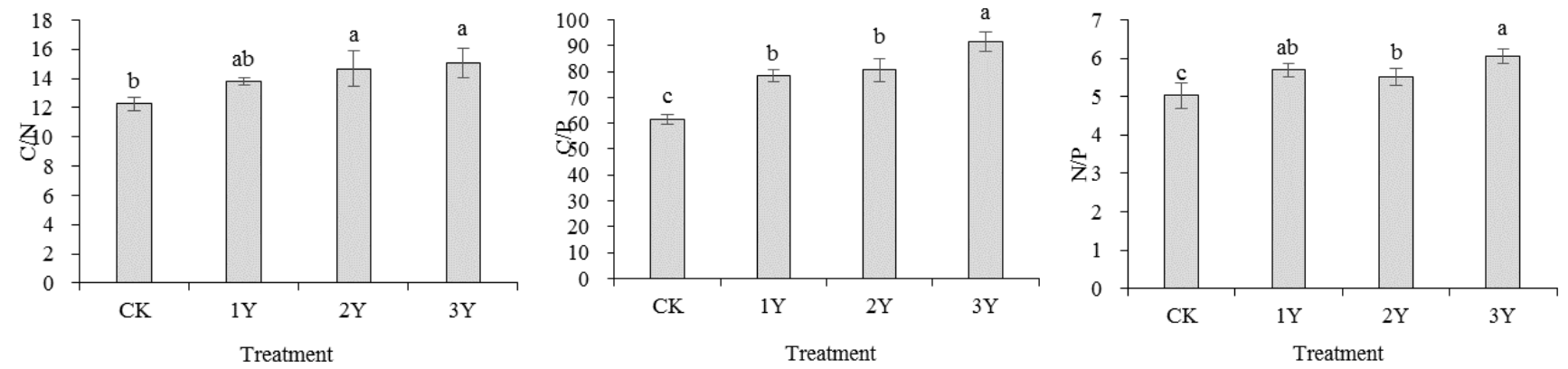

Figure 1: Effect of continuous cropping of D. indusiata on N/P, C/N and N/P ratio in soil

The $\mathrm{C} / \mathrm{N}$ ratio of $1 \mathrm{Y}$ was $12.28 \%$ higher than that of $\mathrm{CK}$, but it did not reach the significant level $(P<0.05)$. The $\mathrm{C} / \mathrm{N}$ ratio of $2 \mathrm{Y}$ was $19.55 \%$ and $6.48 \%$ higher than that of $\mathrm{CK}$ and $1 \mathrm{Y}$, respectively. The $\mathrm{C} / \mathrm{N}$ ratio of $3 \mathrm{Y}$ was $23.01 \%$ and $9.56 \%$ higher than that of $\mathrm{CK}$ and $1 \mathrm{Y}$, respectively, and there was no significant difference with $2 \mathrm{Y}$. The $\mathrm{C} / \mathrm{P}$ ratio of $1 \mathrm{Y}, 2 \mathrm{Y}$ and $3 \mathrm{Y}$ increased by $27.39 \%, 30.90 \%$ and $48.73 \%$, respectively, compared with $\mathrm{CK}$, and all of them reached significant level $(P<0.05)$. $\mathrm{C} / \mathrm{P}$ ratio of $3 \mathrm{Y}$ also increased significantly compared with $1 \mathrm{Y}$ and $2 \mathrm{Y}$, and there was no significant difference between $1 \mathrm{Y}$ and $2 \mathrm{Y}$. The N/P ratio increased significantly after continuous cropping of $D$. indusiata. Compared with CK, the N/P ratio of $1 \mathrm{Y}, 2 \mathrm{Y}$ and $3 \mathrm{Y}$ increased by $13.29 \%, 9.49 \%$ and $20.61 \%$, respectively, and ranked as: $3 \mathrm{Y}>1 \mathrm{Y}>2 \mathrm{Y}>\mathrm{CK}$.

\subsection{Soil Enzyme Activities}

The soil enzyme activity increased first and then decreased with the increase of continuous cropping years (table 3 ). Soil urease, catalase, peroxidase, sucrase, phosphatase and protease activities had maximum values at $1 \mathrm{Y}$, which increased by $74.14 \%, 35.80 \%, 39.19 \%, 62.41 \%, 13.41 \%$ and $20.13 \%$, respectively, compared with $\mathrm{CK}$, and reached significant levels $(P<0.05)$. The catalase and peroxidase activities of $1 \mathrm{Y}, 2 \mathrm{Y}$ and $3 \mathrm{Y}$ were higher than those of $\mathrm{CK}$, but decreased with the increase of continuous cropping years. There was no significant difference between $\mathrm{CK}, 2 \mathrm{Y}$ and $3 \mathrm{Y}$ in protease activity, but significantly lower than $1 Y(P<0.05)$. The urease, sucrase and phosphatase activities of $3 \mathrm{Y}$ decreased by $9.39 \%, 12.97 \%$ and $12.15 \%$, respectively, compared with $\mathrm{CK}$. There was no significant difference in the activities of polyphenoloxidase between $1 \mathrm{Y}, 2 \mathrm{Y}$ and $3 \mathrm{Y}$, but they were $41.72 \%, 48.73 \%$ and $45.61 \%$ higher than that of the control respectively, and reached significant level $(P<0.05)$. 
Table 3: Effect of different treatments on soil enzyme activities

\begin{tabular}{cccccccc}
\hline Treatment & $\begin{array}{c}\text { Urease } \\
(\mathrm{mg} / \mathrm{g})\end{array}$ & $\begin{array}{c}\text { Catalase } \\
(\mathrm{ml} / \mathrm{g})\end{array}$ & Peroxidase $(\mathrm{mg} / \mathrm{g})$ & $\begin{array}{c}\text { Sucrase } \\
(\mathrm{mg} / \mathrm{g})\end{array}$ & Phosphatase $(\mathrm{mg} / \mathrm{g})$ & Protease $(\mathrm{mg} / \mathrm{g})$ & $\begin{array}{c}\text { Polyphenoloxidase } \\
(\mathrm{mg} / \mathrm{g})\end{array}$ \\
\hline $\mathrm{CK}$ & $0.607 \mathrm{bc}$ & $4.207 \mathrm{c}$ & $5.877 \mathrm{c}$ & $10.56 \mathrm{~b}$ & $6.913 \mathrm{~b}$ & $1.207 \mathrm{~b}$ & $0.513 \mathrm{~b}$ \\
$1 \mathrm{Y}$ & $1.057 \mathrm{a}$ & $5.713 \mathrm{a}$ & $8.180 \mathrm{a}$ & $13.97 \mathrm{a}$ & $7.840 \mathrm{a}$ & $1.450 \mathrm{a}$ & $0.727 \mathrm{a}$ \\
$2 \mathrm{Y}$ & $0.717 \mathrm{~b}$ & $5.017 \mathrm{~b}$ & $7.443 \mathrm{ab}$ & $9.990 \mathrm{bc}$ & $6.980 \mathrm{~b}$ & $1.250 \mathrm{~b}$ & $0.763 \mathrm{a}$ \\
$3 \mathrm{Y}$ & $0.550 \mathrm{c}$ & $4.450 \mathrm{c}$ & $6.963 \mathrm{~b}$ & $9.190 \mathrm{c}$ & $6.073 \mathrm{c}$ & $1.163 \mathrm{~b}$ & $0.747 \mathrm{a}$ \\
\hline
\end{tabular}

\subsection{Soil Microbial Biomass}

The biomasses of bacteria, fungi and the total microorganisms in soil were increased after continuous cropping of $D$. indusiata (Table 4). The bacterial and total microorganisms biomass in soil were increased first and then decreased with the increase of continuous cropping years, ranked as: $1 \mathrm{Y}>$ $2 \mathrm{Y}>3 \mathrm{Y}>\mathrm{CK}$. Compared with $\mathrm{CK}$, the bacterial biomass of $1 \mathrm{Y}, 2 \mathrm{Y}$ and $3 \mathrm{Y}$ were increased by $40.10 \%, 20.99 \%$ and $9.30 \%$, respectively, the total microorganisms biomass was increased by $52.52 \%, 39.08 \%$ and $29.78 \%$, respectively, and reached significant level $(P<0.05)$. The biomass of soil actinomycetes was higher than that of $\mathrm{CK}$ at $1 \mathrm{Y}$, and significantly increased by $29.46 \%$. There was no significant difference between the actinomycetes biomass in $2 \mathrm{Y}$ and CK, but it was significantly lower than 1 Y. Soil fungi biomass was increased with the increase of continuous cropping years, ranked as: $3 \mathrm{Y}>2 \mathrm{Y}>1 \mathrm{Y}>\mathrm{CK}$, and reached significant level $(P>0.05)$.

Table 4: Effects of continuous cropping of D. indusiata on soil microbial biomass

\begin{tabular}{ccccc}
\hline Treatment & $\begin{array}{c}\text { Bacteria } \\
(\mathrm{nmol} / \mathrm{g})\end{array}$ & $\begin{array}{c}\text { Actinomycetes } \\
(\mathrm{nmol} / \mathrm{g})\end{array}$ & $\begin{array}{c}\text { Fungi } \\
(\mathrm{nmol} / \mathrm{g})\end{array}$ & $\begin{array}{c}\text { Total microorganisms } \\
(\mathrm{nmol} / \mathrm{g})\end{array}$ \\
\hline $\mathrm{CK}$ & $37.63 \mathrm{~d}$ & $8.453 \mathrm{~b}$ & $13.09 \mathrm{~d}$ & $64.81 \mathrm{~d}$ \\
$1 \mathrm{Y}$ & $52.72 \mathrm{a}$ & $10.94 \mathrm{a}$ & $22.91 \mathrm{c}$ & $98.85 \mathrm{a}$ \\
$2 \mathrm{Y}$ & $45.50 \mathrm{~b}$ & $7.747 \mathrm{~b}$ & $27.64 \mathrm{~b}$ & $90.14 \mathrm{~b}$ \\
$3 \mathrm{Y}$ & $41.13 \mathrm{c}$ & $3.123 \mathrm{c}$ & $32.49 \mathrm{a}$ & $84.11 \mathrm{c}$ \\
\hline
\end{tabular}

\subsection{Proportion of Soil Microbial Species}

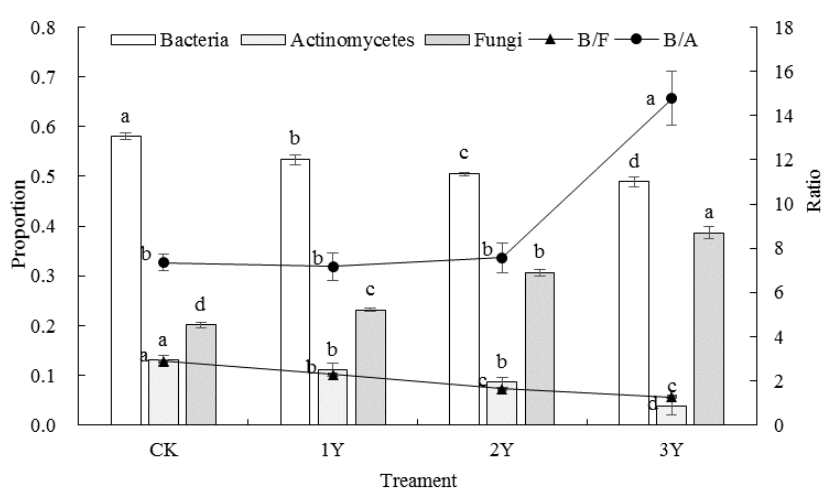

Figure 2: Effects of of continuous cropping of $D$. indusiata on the proportion of soil microbial species

Figure 2 shows the proportion of bacteria and actinomycetes in soil were decreased with the increase of continuous cropping years, had the minimum at $3 \mathrm{Y}$, which decreased by $15.83 \%$ and $71.76 \%$, respectively, compared with $\mathrm{CK}$, and reached significant levels $(P<0.05)$. In contrast to bacteria and actinomycetes, the proportion of fungi in soil increased significantly with the increase of continuous cropping years $(P<0.05)$. Compared with $\mathrm{CK}$, the fungi proportion of $1 \mathrm{Y}$, $2 \mathrm{Y}$ and $3 \mathrm{Y}$ increased by $14.85 \%, 51.98 \%$ and $91.09 \%$, respectively. With the increase of continuous cropping years, the bacteria/fungi ratio in soil gradually decreased, and minimum at $3 \mathrm{Y}$, which were $55.95 \%, 44.94 \%$ and $23.07 \%$ lower than $\mathrm{CK}, 1 \mathrm{Y}$ and $2 \mathrm{Y}$, respectively, and reached significant level $(P<0.05)$. The bacteria/actinomycetes ratio in soil was significantly higher than that of other treatments at $3 \mathrm{Y}$, and there was no significant difference among CK, $1 \mathrm{Y}$ and $2 \mathrm{Y}(P>0.05)$.

\section{Discussion}

\subsection{Continuous-cropping of $D$. indusiata on Soil Physicochemical Properties}

The species and contents of the original mineral nutrients in the soil environment are fixed, and the crops have a specific absorption law to it. With the increase of continuous cropping years, the elements needed more by crops will be reduced in soil, while the elements that are not absorbed by crops will be enhanced, which causing the imbalance of soil nutrients (Ma et al. 2016). The TN, AN, TP, AP, TK and AK of Solanum tuberosum were decreased with the increase of continuous cropping years (Du et al. 2012). With the increase of continuous cropping years of Cucumis sativus in facility cultivation, the soil $\mathrm{pH}$ decreased, the contents of organic matter and available Fe increased, while the contents of available $\mathrm{Mn}, \mathrm{Zn}$ and other trace elements decreased (Zhang 2017). In this experiment, soil $\mathrm{pH}$ was decreased with the increase of continuous cropping years, but it was consistent with the studies of Phallus echinovolvatus. Soil $\mathrm{pH}$ is mainly related to the content of soil organic acids, and it is possible to secrete a large amount of organic acids during the growth of $D$. indusiata, but with the increase of continuous cropping years, it increased the accumulation of soil organic acids, resulting in the decrease of soil $\mathrm{pH}$ value. Compared with $\mathrm{CK}$, the content of AN decreased at $2 \mathrm{Y}$ and $3 \mathrm{Y}$, but the contents of soil SOM, SOC, TN, TP, AN, AP and AK were increased. Compared with the unplanted soil, it was found that the contents of organic matter and mineral elements in the soil were higher than those in the control (Liang et al. 2019). This may be due to the $D$. indusiata belongs to saprophytic bacteria, and the organic matter and mineral elements of the soil increase after planting. Soil AN, AP and AK contents reached the highest at $1 Y$, but decreased after continuous cropping, and their soil TN, TP and TK reached the highest at $3 \mathrm{Y}$. This shows that after planting $D$. indusiata one year, the TN accumulation of soil increased the nitrification of soil, which led to the increase of soil alkali-hydrolyzed nitrogen content, while after continuous cropping, the oxygen consumption of soil was greatly increased, denitrification was enhanced, nitrate was reduced in large quantities, resulting in the loss of soil alkali-hydrolyzed nitrogen. The ratio of $\mathrm{C}, \mathrm{N}$ and $\mathrm{P}$ in the soil increased after the continuous cropping of $D$. indusiata, which 
resulted in the imbalance of the ratio of $\mathrm{C}, \mathrm{N}$ and $\mathrm{P}$ in the soil, and further directly reduced the yield of $D$. indusiata, which indicated that continuous cropping of D. indusiata had an adverse effects on the balance and synergy of the main nutrients in the soil, it was one of the main causes of soil degradation and the lower yield of $D$. indusiata.

\subsection{Continuous-cropping of $D$. indusiata on Soil Microbial Biomass}

After continuous cropping, the management mode was basically consistent, which led to the directional change of soil environment, and caused the loss of some nutrient elements, the harmful microorganism increased year by year, the beneficial microorganism decreased year by year, and finally destroyed the soil health level (Ma et al. 2004). It has been found that with the increase of continuous cropping years, the biomass of bacteria in soil microbe was decreased, but contrary to fungi biomass, which led to multiply some parasitic bacteria, and finally aggravates crop diseases (Guo et al. 2016). In this experiment, the biomasses of bacteria, actinomycetes, fungi and the total microorganisms in $1 \mathrm{Y}$ were higher than CK. With the increase of continuous cropping years, the biomasses of bacteria and actinomycetes and total microorganisms had a reduce trend, while the biomasses of fungi increased. This may be because the soil nutrient availability increased after the planting of $D$. indusiata, thus the soil microbial biomass increased, and with the increase of continuous cropping years, the formation of specific soil environment and Rhizosphere conditions affects the reproduction and activity of soil and rhizosphere microorganisms, resulted the fungal enrichment, soil fertility changes. After continuous cropping, the proportion of bacteria/fungi decreased and the proportion of fungi increased, and bacterial soil transformed into fungal soil. Some studies have shown that fungal soil as a markers of soil fertility failure, and bacterial soil to be a biological indicator of soil fertility improvement (Li et al. 2006). As similar to previous studies, continuous cropping of Ophiopogon japonicus decreased the biomasses of bacteria and actinomycetes in soils, while the biomasses of fungi increased with the increase of continuous cropping years (Zhang et al. 2016). Analyzed the changing trend of yield by sterilizing the soil of Glycine max every time, and found that the main reason for the reduction of G. max after continuous cropping was the change of growth environment (Hassan et al. 1989). After continuous cropping of Citrullus lanatus, the soil microflora also changed, with the increase of continuous cropping years, the biomasses of bacteria and actinomycetes in soil increased first and then decreased, while the biomasses of fungi decreased first and then increased (Zhao et al. 2008).

\subsection{Continuous-cropping of D. indusiata on Soil Enzyme Activities}

Soil enzyme activity is an important index to evaluate the soil fertility, and the function of soil enzyme can not be separated from the material circulation of C, N, P, K and other elements (Cao et al. 2008). Soil enzymes mainly come from microorganisms, plant root exudates and the release of soil animal and plant residues. In addition, soil enzyme activity is also affected by many factors, such as environment and fertilizer, and there is a relationship between substrate and product of various soil enzymes (Qiu et al. 2004). In this experiment, the soil enzyme activity of $1 \mathrm{Y}$ was higher than that of $\mathrm{CK}$, but decreased in different degree with the increase of continuous cropping years except polyphenoloxidase. The decrease of soil enzyme activity may be related to the fungi properties of $D$. indusiata, and SOC releases specific plant nutrients under the action of various enzymes. Studies have shown a positive correlation between soil enzyme activity and soil nutrient availability (Chen et al. 2015). In this study, the soil nutrient availability was decreased after continuous cropping, which may lead to the decrease of soil enzyme activity. Studies have shown that the correlation between soil microbial biomass and soil phosphatase, catalase and urease activity has reached an extremely significant or significant level, which indicates that soil enzyme activity is related to soil microbial biomass (Zhao et al. 2010). The total microorganisms decreased with the increase of continuous cropping years, which also may be one of the reasons for the decrease of soil enzyme activity. The changes of soil enzyme activity were different with cropping of different plants. After continuous cropping of Rehmannia glutinosa, the activities of urease, protease, polyphenoloxidase, sucrase and cellulase in soil showed an increasing trend, but the catalase activity in soil showed a decreasing trend (Chen et al. 2007). In the study of soil enzyme activity of Poria cocos, the activity of urease, acid phosphatase, dehydrogenase and catalase in soil were decreased with the increase of continuous cropping years ( $\mathrm{Yu}$ et al. 2009).

\section{Conclusion}

The contents of soil SOC, TN, TP, TK, the $\mathrm{C} / \mathrm{N}$ and $\mathrm{C} / \mathrm{P}$ ratio were improved by continuous cropping of $D$. indusiata, besides, the trend was increasing with the increase of continuous cropping years. The nutrients availability and $\mathrm{pH}$ in soil were decreased with the increase of continuous cropping years. The continuous cropping of $D$. indusiata transformed the soil from bacterial to fungal, the contents of bacteria, actinomycetes and total microorganisms were decreased with the increase of continuous cropping years, while the content of fungi increased. Continuous cropping could reduce the soil urease, catalase, peroxidase, sucrase, phosphatase and protease activity, but it has no significant effect on soil polyphenol oxidase. The results showed that the continuous cropping of $D$. indusiata will reduce the soil texture, it not conducive to the production of $D$. indusiata under bamboo forests.

\section{References}

[1] Bao S D. (2000): Soil agrochemical analysis (Third Edition), Beijing: China Agriculture Press.

[2] Cai X L, Wang D Y, He W, An F Q. (2015): Research advances on biological characteristics and cultivation technique of Dictyphora. Journal of Anhui Agricultural Sciences, 43(7): 65-66. 
[3] Cao B H., Wu L Y. (2008): Studies on soil enzyme activity and soil nutrient content of mixed stands with Robinia pseudoacacia and Frax inus velutina in coastal saline soil. Journal of Soil and Water Conservation, 22(1): 129-130.

[4] Chai Z P., Liang Z., Wang X M., Jia H T. (2008): The influence of the continuous cropping to the physical properties of cotton soil. Chinese Agricultural Science Bulletin, (8): 192-195.

[5] Chang Y C., Cai W J., Shi Y., Lin S Q., Ye Z. (2013): Dynamic change of soil microorganisms at various growing stage of Dictyophora. Chinese Journal of Tropical Crops, 34(7): 1228-1231.

[6] Chen M., Li X., Yang Q., Wu H L. (2012): Soil eukaryotic microorganism succession as affected by continuous cropping of peanut-pathogenic and beneficial fungi were selected. PLoS One. 7(7): e40659.

[7] Chen S., Qi G F., Luo T., Zhang H C., Jiang Q K., Wang R., Zhao X Y. (2018): Continuous-cropping tobacco caused variance of chemical properties and structure of bacterial network in soils. Land Degradation and Development, 29: 4106-4120.

[8] Cheng D M., Ke W H., Cheng L L., Huang J W., Wu W X., Chen T., Zhang C Y., Lin W X. (2010): Diversity of bacterial community in rhizosphere soils under effects of continuously planting burley tobacco. Chinese Journal of Applied Ecology, 21(7): 1751-1758.

[9] Cheng G F., Liu Z., Huang Y F., Tan Y M., Tang Q Z., Huang T Q., Yang S E., Liao Q., Xing Y., Jiang Z P., Huang Y Y. (2015): Effects of different fertilizer treatments on microbial biomass, enzyme activity and related nutrients in soils of continuous cropping sugarcane field. Journal of Southern Agriculture, 46(12): 2123-2128.

[10] Cheng H., Hao H R., Xiong J., Qi X H., Zhang C Y., Lin W X. (2007): Effects of successive cropping Rehmannia glutinosa on rhizosphere soil microbial flora and enzyme activities. Chinese Journal of Applied Ecology, 18(12): 2755-2759.

[11] Cheng Y X., Lv Y L., Chang Y C., Lei M L., Wu Y L., Ye Z. (2017): Effects of continuous cropping of Dictyophora on soil microflora and enzyme activity. Research Report, 35(12): 136-138.

[12] Dou F G., Wright A L., Mylavarapu R S., Jiang X J., Matocha J B. (2016): Soil enzyme activities and organic matter composition affected by 26 years of continuous cropping. Pedosphere, 26(5): 618-625.

[13] Du Q., Lu D., Ma K. (2012): Effect of potato continuous cropping on soil microbial community structure and function. Ecology and Environmental Sciences, 21(7): 1252-1256.

[14] Gu H S., Guo L., Zeng Z L., Wang B., Qiu P., Cao T M., Chen Y C. (2013): Advances in formation mechanism of continuous cropping obstacles for tobacco planting and its regulation technology. Hunan Agric Sci, (1): 25-28.

[15] Guo X., Kong D Z., Huang B T., Huang B T., Tang Y C., Yang L., Wang M Z., Wang S T., Xiang D B., Zhao G. (2016): Studies on the mechanism and control technology of continuous cropping obstacle. Crop Research, 30(2): 215-220.

[16] Hassan M S., El-Behadli A H., Alsaadawi I S. (1989): Citrus replant problem in Iraq I. Possible role of soil fungi and nematodes. Plant and Soil, 116(2): 151-155.
[17] Hou H., Dong K., Yang Z X., Dong Y., Tang L., Zheng Y. (2016): Advance in mechanism of continuous cropping obstacle. Soils, 48(6): 1068-1076.

[18] Jiang H H. (2011): Discussion on the causes of low yield and poor quality of continuous cropping in the producing area of Dictyophora. Edible and Medicinal Mushrooms, 19(4): 44-46.

[19] Ker Y B.,1 Chen K C., Peng C C., Hsieh C L., Peng R Y. (2011): Structural characteristics and antioxidative capability of the soluble polysaccharides presentin Dictyophora indusiata (Vent.ExPers.) Fish Phallaceae. Evidence-based Complementary and Alternative Medicine, e 396013, 9.

[20] Liang J F., Yu F., Shi J L. (2019): Effects of continuous cropping of phallus echinovolvatus on rhizosphere soil bacteria. Journal of Hunan Ecological Science, 6(2): $1-10$.

[21] Lin C Q., Cheng J S., Lin R B, Lin X J. (2011): Study on the development of the comprehensive utilization about the Dictyophora resource. Edible Fungi of China, 30(2): 8-11.

[22] Liu D H., Wang L., Cui X M., Guo L P., Jin H., Zhu X Y., Yang Y. (2014): Study on dynamic change law of N,P and $\mathrm{K}$ in Panax notoginseng plant soils with different interval year. China Journal of Chinese Materia Medica, 39(4): 572-579.

[23] Lv Y L. (2012): Analysis pn the causes of continuous cropping obstacle of Dictyophora indusiata. MS Thesis. Lanzhou: Fujian Agriculture and Forestry University.

[24] Ma K., Yang G L., Ma L., Wang C M., Wei C H., Dai X H., He W T. (2016): Effects of intercropping on soil microbial communities after long-term potato monoculture. Acta Ecologica Sinica, 36(10): 2987-2995.

[25] Ma Y H., Wei L., Wang X F. (2004): Variation of microflora and enzyme activity in continuous cropping cucumber soil in solar greenhouse. Chinese Journal of Applied Ecology, 15(6): 1005-1008.

[26] Qiu L P., Liu J., Wang Y Q., Sun H M., He W X. (2004): Research on relationship between soil enzyme activities and soil fertility. Journal of Plant Nutrition and Fertilizers, (3): 277-280.

[27] Shi J L. (2018): Effects of Phallus echinovolvatus continuous cropping on soil bacterial community structure and function. MS Thesis. Chinese Academy of Forestry.

[28] Sun Y Y., Jiang G Y., Liu J G., Zhang W., Tang Z M. (2010): Effects of continuous cropping tomato for processing on soil enzyme activities and microbial flora. Acta Ecologica Sinica, 30(13): 3599-3607.

[29] Wan S M., Gao X M., Liu X H., Hu S L. (2012): The influence of the continuous cotton cropping on the physical properties of cotton field in different cropping systems in South Xinjiang. Chinese Agricultural Science Bulletin, 28(12): 48-53.

[30] Wang J Y., Zheng G P., Zhang H Y., Li G L. (1997): Study on the reason of root-shoot ratio increasing of soybean on continuous cropping. Soybean Sci, 16: 136-142.

[31] Wang X B., Luo Y M., Li Z G., Liu W X., He Y Q. (2011): Effects of long-term stationary fertilization experiment on incidence of soil-borne diseases and biological characteristics of peanut in continuous 
monocropping system in red soil area. Acta Pedol Sin, 48: 725-730.

[32] Wu Z F., Cheng B., Wang C B., Zheng Y P., Liu J H., Chen D X., Gao X H. (2006): Effect of continuous cropping on peanut seedling physiological characteristics and pod yield. J Peanut Sci, 35(1): 29-33.

[33] Xu Y L., Liu X B., Han X Z., Li Z L., Wang S Y., He X Y., Yu L. (1999): Effect of continuous-cropping on yield and growth development of soybean. Sci Agric Sin, 32(suppl): 64-68.

[34] Ye Y., Zhang J L., Wang N., Liu Z P., Wang P. (2011): Analysis of dry matter accumulation and production value of flue-cured tobacco by continuous cropping under conventional fertilization. Shandong Agric Sci, (12): 77-79.

[35] Yu S J., Sun H Q., Wang P., Wu H L. 2009. Primary research on variations of microflora and enzyme activity in soil of Tuckahoe cultivation field. Anhui Agriculture Science, 37(16): 7585-7588.

[36] Zhang F. (2017): The relationship between soil microbial diversity and organic mattercomponent of continuous cropping cucumber in solar greenhouse. MS Thesis. Shenyang: Shenyang Agricultural University.

[37] Zhang L Q. (2016): Effect of long-term rotation and fertilization to soil fertility and its comprehensive evaluation. PhD Thesis. Lanzhou: Northwest Agricultural and Forestry University.

[38] Zhao M., Li M., Wang M M., Wang Y., Zhang X Y. (2008): Effects of watermelon replanting on main microflora of rhizosphere and activities of soil enzymes. Institute of Microbiology, 35(8): 1251-1254.

[39] Zhao N., Lin W.P., Cai K.Z., Wang J.W. (2010): Impacts of livestock waste compost on tomato bacterial wilt, soil enzyme activity and soil microbial functional diversity. Acta Ecologica Sinica, 30(19): 5327-5337.

[40] Zheng W C., Cao K Q., Hu T L., Cao A X. (2001): The research advance on crop replant diseases. Journal of Agricultural University of Hebei, 24(4): 98-104. 